\title{
Dynamic Model of Kaplan Turbine Regulating System Suitable for Power System Analysis
}

\author{
Jie Zhao, Li Wang, Dichen Liu, Jun Wang, Yu Zhao, Tian Liu, and Haoyu Wang \\ School of Electrical Engineering, Wuhan University, Wuhan, Hubei 430072, China \\ Correspondence should be addressed to Li Wang; 2009302540275@whu.edu.cn
}

Received 19 August 2015; Revised 17 October 2015; Accepted 18 October 2015

Academic Editor: Filippo Ubertini

Copyright ( 2015 Jie Zhao et al. This is an open access article distributed under the Creative Commons Attribution License, which permits unrestricted use, distribution, and reproduction in any medium, provided the original work is properly cited.

\begin{abstract}
Accurate modeling of Kaplan turbine regulating system is of great significance for grid security and stability analysis. In this paper, Kaplan turbine regulating system model is divided into the governor system model, the blade control system model, and the turbine and water diversion system model. The Kaplan turbine has its particularity, and the on-cam relationship between the wicket gate opening and the runner blade angle under a certain water head on the whole range was obtained by high-order curve fitting method. Progressively the linearized Kaplan turbine model, improved ideal Kaplan turbine model, and nonlinear Kaplan turbine model were developed. The nonlinear Kaplan turbine model considered the correction function of the blade angle on the turbine power, thereby improving the model simulation accuracy. The model parameters were calculated or obtained by the improved particle swarm optimization (IPSO) algorithm. For the blade control system model, the default blade servomotor time constant given by value of one simplified the modeling and experimental work. Further studies combined with measured test data verified the established model accuracy and laid a foundation for further research into the influence of Kaplan turbine connecting to the grid.
\end{abstract}

\section{Introduction}

Hydraulic turbine generator units are increasingly being relied upon to meet a variety of control requirements as the size and complexity of interconnected systems increase. To establish models reflecting the actual characteristics of the prime mover and its governor is an important foundation work for the accuracy of power grid security and stability analysis $[1,2]$. It is necessary to adjust both the wicket gate opening and the runner blade angle under different water head by the governor to keep efficient operation of a Kaplan turbine, which is one of the common forms of turbines in hydropower systems $[3,4]$. There is an urgent need to establish Kaplan turbine regulating system dynamic model suitable for power system analysis based on measured experimental data to obtain the parameters [5].

There have been many studies on the modeling and verification of Francis turbine [6-10]. The common Francis turbine model contains the single regulator system model, the wicket gate control system model, and the turbine and water diversion system model. The ideal turbine model or linearized turbine model reflects the basic characteristics of the prime mover, but the ideal turbine model reflects unit features at rated operating point and the linearized turbine model is suitable for small power fluctuations $[8,9]$.

The operation of Kaplan turbine involves control of the wicket gates and the runner blades position to regulate the water flow into the turbine $[2,11]$. Due to the on-cam relationship between the wicket gate opening and the runner blade angle, the impact of blade angle on Kaplan turbine transient simulation accuracy should not be ignored $[12,13]$. The linear fitting [14], polynomial interpolation and fitting [15], or intelligent algorithm [16] was used to obtain the on-cam relationship expression. However, the linear fitting obtained via limited points [14] to an extent may fail to reflect the function completely. Different Kaplan turbine and water diversion system models based on different functions of wicket gate opening multiplied by function of blade angle as inputs of nonlinear turbine model were compared [17]. The parameter identification of a turbine and water 
diversion system model may become difficult with highorder fitting function of the wicket gate opening or the blade angle. As a result, the applicability of the established model declines.

The Kaplan turbine regulating system model contains the mathematical models of the governor, the dual-regulated vane control system and blade control system, and the turbine and water diversion system. In this paper, the Kaplan turbine regulating system dynamic model and parameters were optimized suitable for power system analysis, experimental measurement, and precision requirements. The main contribution lies in the blade control system model simplification, the on-cam relationship obtainment, the derived five-parameter linearized Kaplan turbine model, parameter obtainment method, and different Kaplan turbine regulating system dynamic models comparison in gird connected system. The structure is organized as follows. In Section 2, the Kaplan turbine regulating system model is presented. Section 3 contains the development of three kinds of Kaplan turbine and water diversion system model (i.e., the linearized Kaplan turbine model, the improved ideal turbine model, and the nonlinear Kaplan turbine model). The established model is verified by comparison with the measured data in Section 4. The results and discussion are presented in Section 4 as well. Section 5 presents the conclusions drawn thereof.

\section{Kaplan Turbine Regulating System Mathematical Model}

Figure 1 shows the frame diagram of hydroelectric power with double-regulated turbine [18]. The vane control system is based on the same principle of Francis turbine. The on-cam relationship presents the runner blade angle changes with the wicket gate opening and the blade is kept in a certain best angle fitting with the wicket gate opening to improve the power generation efficiency.

$\omega$ and $\omega_{\text {ref }}$ are the unit frequency and given frequency value, respectively, and $P_{\text {ref }}$ and $P_{e}$ are the given power and turbine load, respectively. $y_{\text {ref }}, y$, and $y_{r}$ are the given wicket gate opening, the actual wicket gate opening, and the blade opening, respectively. The blade opening is transferred from the blade angle with the maximum value no more than one. $q$ is the turbine working flow, $h$ is the turbine working head, and $P_{m}$ is the mechanical power output.

2.1. The Regulating System Model. The Kaplan turbine governor system is consistent with that of the general Francis turbine. Figure 2 shows the digital governor model. Also, Figure 3 shows the vane control system model considering the speed limit and the amplitude limit [18]. $K_{P}, K_{I}$, and $K_{D}$ are the proportional, integral, and differential coefficients of the governor, respectively. $K_{s p}, K_{s i}$, and $K_{s d}$ are the proportional, integral, and differential coefficients of the integrated amplifier module, respectively. $e_{p}$ is the power deviation magnification. $T_{y}$ is the main servomotor time constant. $\mathrm{VEL}_{\text {open }}$ and $\mathrm{VEL}_{\text {close }}$ are the open and close servomotor speed limits, respectively. $y_{g \mathrm{MAX}}$ and $y_{g \mathrm{MIN}}$ are the limiting values of the wicket gate opening.
2.2. Blade Control System Model. The principle of the blade control system is similar to that of the vane control system, assuming that the on-cam relationship between the wicket gate opening and the runner blade angle is neglected [19]. The blade control valve adopts a proportional valve to handle the blade servomotor. Figure 4 shows the blade control system model under a certain water head. $T_{y r}$ is the blade servomotor time constant. $\mathrm{VEL}_{\text {open1 }}$ and $\mathrm{VEL}_{\text {close1 }}$ are the open and close servomotor speed limits, respectively. $y_{r \text { MAX }}$ and $y_{r \text { MIN }}$ are the limiting values of the blade opening.

The function between the blade opening, the gate opening, and the water head is expressed as

$$
y_{r}=f(y, H) .
$$

Under a certain water head, the function of the wicket gate opening and the runner blade opening is given by

$$
y_{r}=a_{5} y^{5}+a_{4} y^{4}+a_{3} y^{3}+a_{2} y^{2}+a_{1} y+a_{0},
$$

where $a_{5}, a_{4}, a_{3}, a_{2}, a_{1}$, and $a_{0}$ are the fitting coefficients.

\section{Kaplan Turbine and Water Diversion System Model}

The linearized Kaplan turbine model, improved ideal turbine model, and nonlinear Kaplan turbine model were developed. The five-parameter linearized Kaplan turbine model was derived for parameters obtainment convenience. The improved ideal turbine model and nonlinear turbine model were demonstrated based on the principle of the turbine that the blade opening affected the Kaplan turbine power like the linearized turbine model did.

3.1. Model One: Linearized Kaplan Turbine Model. The dynamic characteristic of hydraulic turbine is associated with the dynamic characteristic of the water flow in the pipe. The turbine characteristics in the vicinity of the operating point are approximately linear. Compared with the Francis turbine [9], the torque and water flow of Kaplan turbine can be expressed as

$$
\begin{aligned}
& m_{t}=e_{x} x+e_{y} y+e_{r} y_{r}+e_{h} h, \\
& q=e_{q x} x+e_{q y} y+e_{q r} y_{r}+e_{q h} h,
\end{aligned}
$$

where $e_{x}, e_{y}, e_{r}$, and $e_{h}$ are the transfer coefficients of turbine torque to the rotational speed, wicket gate opening, blade opening, and water head, respectively. $e_{q x}, e_{q y}, e_{q r}$, and $e_{q h}$ are the transfer coefficients of the water flow to the rotational speed, wicket gate opening, blade opening, and water head, respectively.

For the turbine water diversion system, considering the wall elasticity of water flow and water diversion system and ignoring the friction between them, the mathematical model of water diversion system can be obtained as [6]

$$
G_{h}(s)=\frac{2 T_{w}}{T_{r}} \frac{1-e^{T_{r} s}}{1+e^{T_{r} s}},
$$




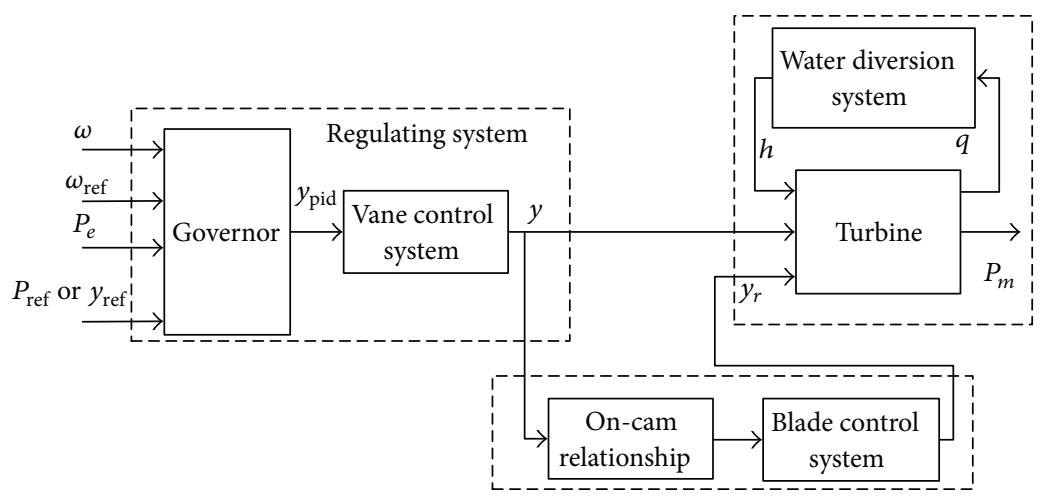

FIGURE 1: Kaplan turbine regulating system frame diagram.

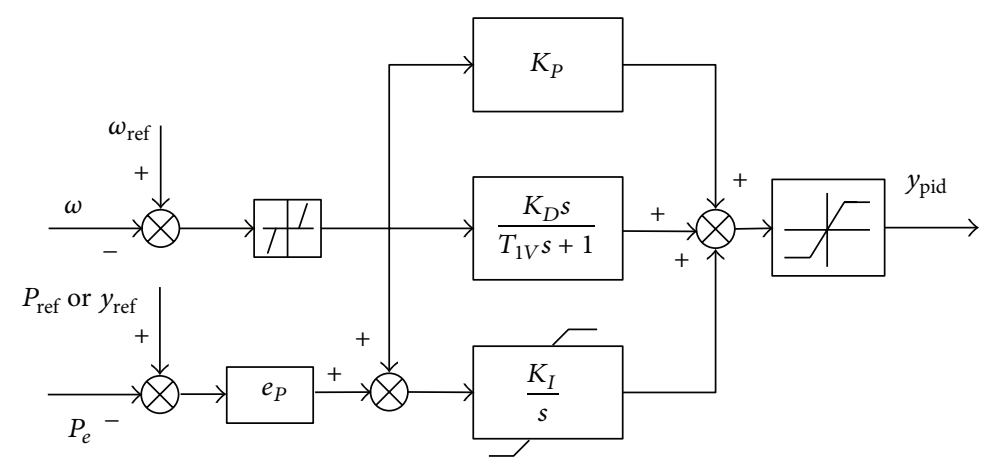

FIGURE 2: Kaplan turbine governor model.

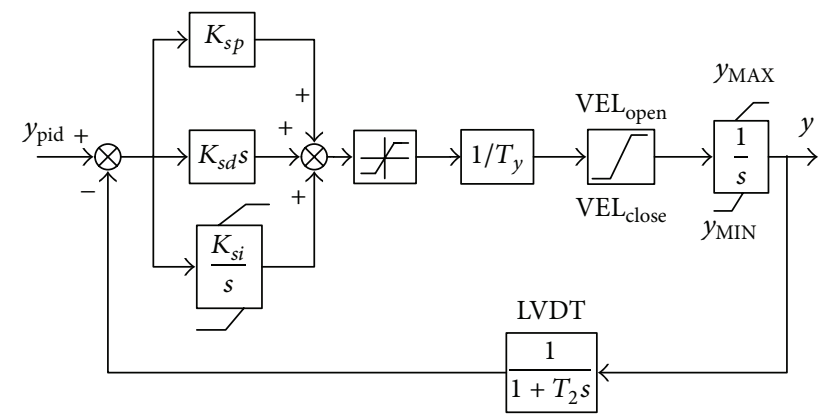

Figure 3: Kaplan turbine vane control system model.

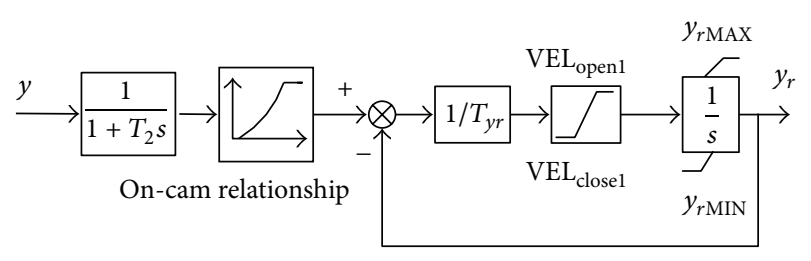

Figure 4: Blade control system model.

where $T_{w}$ is the water inertia time constant and $T_{r}$ is the water hammer phase length.
If the high level terms in the Taylor expression of (4) are ignored, then the transfer function of the simplified elastic model is given as

$$
G_{h}(s)=-\frac{T_{w} s\left(1+(1 / 24) T_{r}^{2} s^{2}\right)}{1+(1 / 8) T_{r}^{2} s^{2}} .
$$

Furthermore, if the flexibility of the water flow and the water diversion pipe is ignored, the transfer function of the rigid water hammer model is expressed as

$$
G_{h}(s)=-T_{w} s .
$$

The speed influence on the turbine power in (3) is neglected due to the little unit speed change under the grid connected condition. Figure 5 shows the linearized Kaplan turbine model and its deformed five-parameter linearized turbine model with rigid water hammer model, while $a, b$, $c, d$, and $f$ are constants above zero.

3.2. Model Two: Improved Ideal Turbine Model. Assume that the transfer coefficients in (3) and the turbine efficiency are certain under various working conditions and the wicket gate opening varies linearly. Ignoring the unit speed influence on turbine power, the ideal turbine model of the Francis turbine at rated operating point is described as [8]

$$
G(s)=\frac{1-T_{w} s}{1+0.5 T_{w} s} .
$$




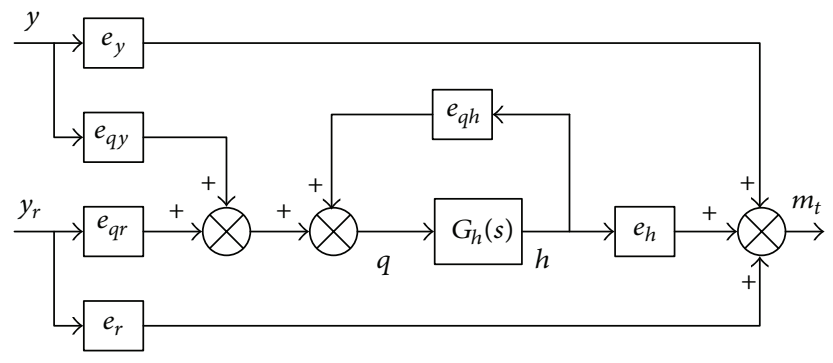

(a)

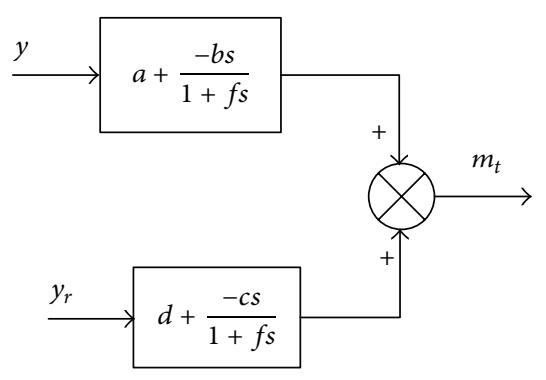

(b)

FIGURE 5: Linearized Kaplan turbine model. (a) Linearized Kaplan turbine model. (b) Five-parameter linearized turbine model.

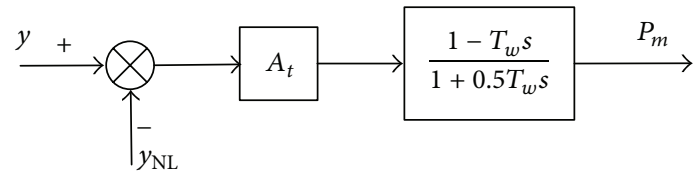

FIGURE 6: Improved ideal turbine model.

Figure 6 shows the improved ideal turbine considering the effect of the wicket gate and the blade on Kaplan turbine power. $y_{\mathrm{NL}}$ is the equivalent no-load opening. $A_{t}$ is the proportional coefficient. The blade effect on the Kaplan turbine power is reflected by the calculation of $A_{t}$ and $y_{\mathrm{NL}}$, which are identified by an optimization algorithm in this paper.

3.3. Model Three: Nonlinear Kaplan Turbine Model. For the Francis turbine, considering the relationship between the turbine flow, wicket gate opening, and the water head as a valve [19], the nonlinear turbine model is described by

$$
\begin{aligned}
q & =y \sqrt{h}, \\
P_{m} & =k_{p}\left(q-q_{0}\right) h, \\
\dot{q} & =\frac{1}{G_{h}(s)}\left(h-h_{0}\right),
\end{aligned}
$$

where $q$ is the water flow in the diversion pipeline, $\dot{q}$ is the derivative of $q, h_{0}$ is the static head (its per unit value is 1 ), and $q_{0}$ is no-load flow. $k_{p}$ is proportional coefficient.

The nonlinear Kaplan turbine model is established based on the following four aspects:

(a) Under the normal grid connected operation, the unit speed is generally in the vicinity of rated speed, so the unit speed impact on the turbine model is ignored.

(b) The hydraulic turbine with the water diversion pipe length less than $800 \mathrm{~m}$ can adopt the rigid water hammer model to simulate the dynamic process of the water diversion pipe.

(c) Consider the nonlinear relationship between the wicket gate opening and the turbine mechanical power.

(d) The effect of the blade opening on the Kaplan turbine is viewed as increasing flow amount.
The variable $G$ is introduced to represent the equivalent opening for the combined effect of the wicket gate opening and the blade opening given by

$$
G=f(y) \cdot f\left(y_{r}\right),
$$

where $f(y)$ and $f\left(y_{r}\right)$ are the function of $y$ and $y_{r}$, respectively.

Different to the Kaplan turbine and water diversion system models based on concrete different functions of $y$ and $y_{r}$ [17], function $f(y)$ is represented by cubic polynomial fitting and function $f\left(y_{r}\right)$ is represented by linear fitting given by

$$
\begin{aligned}
& f(y)=b_{3} y^{3}+b_{2} y^{2}+b_{1} y+b_{0}, \\
& f\left(y_{r}\right)=y_{r} \cdot B_{\text {flow }}+1
\end{aligned}
$$

where $b_{3}, b_{2}, b_{1}$, and $b_{0}$ are the fitting coefficients. $B_{\text {flow }}$ is the coefficient representing the blade angle impact on the turbine water flow. Herein the effect of the blade opening on the turbine is considered as incremental flow referring to the principle of Kaplan turbine and the parameters in (10) are easy to obtain for engineering application and model validation, which reflects the nonlinear characteristics and working principle of Kaplan turbine.

There is a time delay between the wicket gate movement and the consequent blade angle movement in the case studied. Figure 7 shows the nonlinear Kaplan turbine model with rigid water hammer model considering the above four aspects combined with (8)-(10).

\section{Results and Discussion}

The testing of the Kaplan turbine regulating system model is based on the Kaplan turbine at Tukahe hydropower plant in Yunnan province of West China. The hydropower station has three units with one unit capacity of $55 \mathrm{MW}$, normal reservoir storage level of $368 \mathrm{~m}$, and rated head of $25 \mathrm{~m}$.

Different fitting functions of on-cam relationship were compared based on the whole range measured under given wicket gate opening disturbances while the gate-runner relationship was determined from the turbine characteristics (TC) data in [17]. The blade control effect is mainly determined by the on-cam relationship, speed limits, and blade 


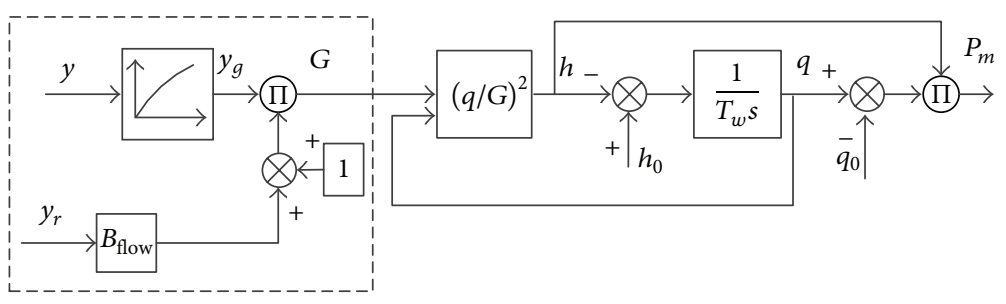

FIGURE 7: Kaplan turbine and water diversion system model.

servomotor time constant of the blade control system model. The default blade servomotor time constant given by value of one simplified the modeling and experimental work. The Kaplan turbine regulating system dynamic model and three different turbine and water diversion system models were compared for stability analysis in the grid connected power system.

4.1. On-Cam Relationship Validation of Wicket Gate Opening and Blade Opening. The fifth order polynomial fitting of the on-cam relationship between the wicket gate opening and the blade opening based on the measured data near the rated water head is expressed as

$$
\begin{aligned}
y_{r}= & 24.36 y^{5}-76.29 y^{4}+83.92 y^{3}-37.77 y^{2} \\
& +7.187 y-0.4525 .
\end{aligned}
$$

The blade opening is set to a certain value near zero when wicket gate opening is less than $40 \%$. The best fitting function is obtained through measured data depending on different Kaplan turbines or different working heads. The relationship between the wicket gate opening and the blade opening needs to be revised with appropriate polynomial fitting at other working heads. Figure 8(a) shows the simulated blade opening of the blade control system model (see Figure 4) using the expression in (11) under given wicket gate opening disturbances of whole range.

As shown in Figure 8(a), when the wicket gate opening is less than 0.4 by per unit value, the blade opening is approximate to zero and the maximum blade opening is about 0.9 by per unit value. The piecewise linear fitting result fits with the measured data when the wicket gate opening is less than 0.6 and has a difference as the wicket gate opening over 0.6 by per unit value. The fifth order fitting shown in (11) is closest to the measured data which shows a better on-cam relationship than the other fitting methods. Given the wicket gate opening disturbances, the simulation result using fifth order fitting is consistent with the measured data in the whole operating range (see Figure $8(\mathrm{c})$ ) and verifies the correctness of the on-cam relationship function.

\subsection{Influence of Blade Servomotor Time Constant on the Blade} Control System Model. The influence of blade servomotor time constant on the blade control system model was studied. Figure 9 shows the simulation results with different $T_{y r}$ values.

The influence of different $T_{y r}$ values on the simulation results shows that the bigger $T_{y r}$ is, the slower adjusted rate is (see Figure 9), and thus $T_{y r}$ should be as small as possible. Due to the rate restrictions of $\mathrm{VEL}_{\text {open1 }}$ and $\mathrm{VEL}_{\text {close1 }}$, the result difference is not obvious when $T_{y r}$ is less than $1 \mathrm{~s}$. In conclusion, the blade servomotor time constant affects the adjustment of blade control system model and should be set in a reasonable range of value. $T_{y r}$ in this case is $1 \mathrm{~s}$ considering that it is difficult to be tested. When $T_{y r}$ is about 1 s (i.e., the blade servomotor response time link is ignored), it has little effect on the simulation result but simplifies the modeling and experimental work.

4.3. Turbine Regulating System Model Validation. The improved particle swarm optimization (IPSO) algorithm (i.e., the inertia weight is linearly changed and the chaos method is used to generate initial particle population) is applied to identify the model parameters [20]. The inertia weight is introduced to revise the speed update equation to improve search ability in the global scope. The chaos method is used to generate good initial particle population.

The error evaluation index to quantize the simulation agreement is defined as

$$
\sigma=\frac{\sum_{i=1}^{N}\left(Y_{i}-\widehat{Y}_{i}\right)^{2}}{N},
$$

where $Y_{i}$ is $i$ th measured value, $\widehat{Y}_{i}$ is $i$ th simulation value, and $N$ is the total number of sampling points.

Figure 10 shows the graphical representation of measured behavior of power acquired at a certain head given in $2 \mathrm{D}$ and $3 \mathrm{D}$ space. $y_{r}$ changes with $y$ when the wicket gate opening is over a certain value. In addition, the relationship between the wicket gate opening and the turbine mechanical power is nonlinear.

The speed limits and amplitude limits of the vane control system and blade control system were calculated under large wicket gate opening disturbances while other parameters were identified by the improved particle swarm optimization (IPSO) algorithm under small wicket gate opening disturbances and the parameters were revised through grid connected simulation comparison. The maximum iteration step of IPSO algorithm is 100 . For the error function with the extreme point of zero, the tolerance of error is set to $10^{-6}$. The parameters generally range from slightly greater than 0 to 100 to get global solution as much as possible. Based on the turbine power disturbance test data and the unit frequency disturbance test data, Table 1 lists the cubic fitting relation between variables $y_{g}$ and $y$ (see Figure 7), the coefficient representing blade angle impact on the turbine water flow, 


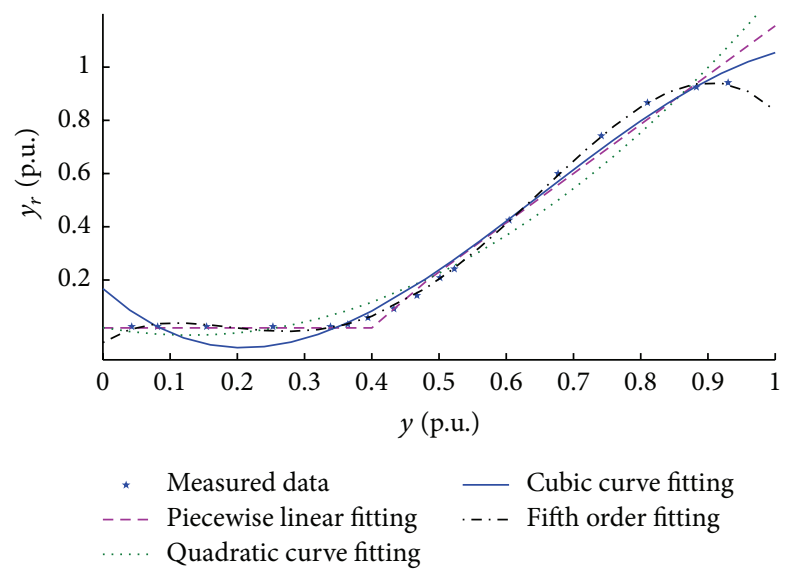

(a)

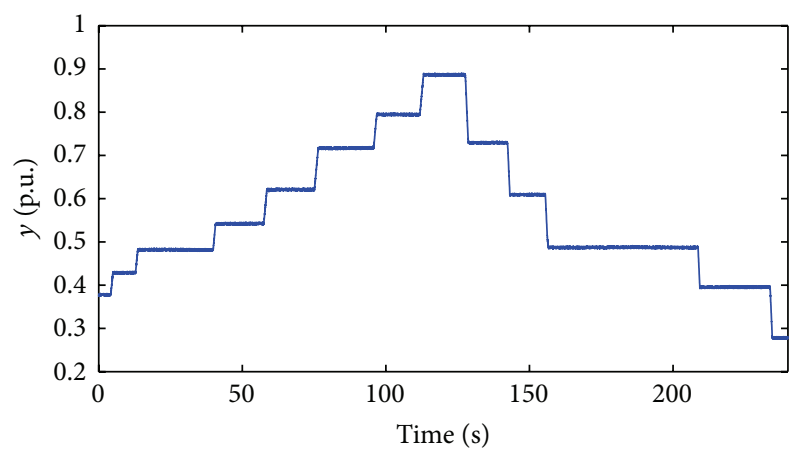

(b)

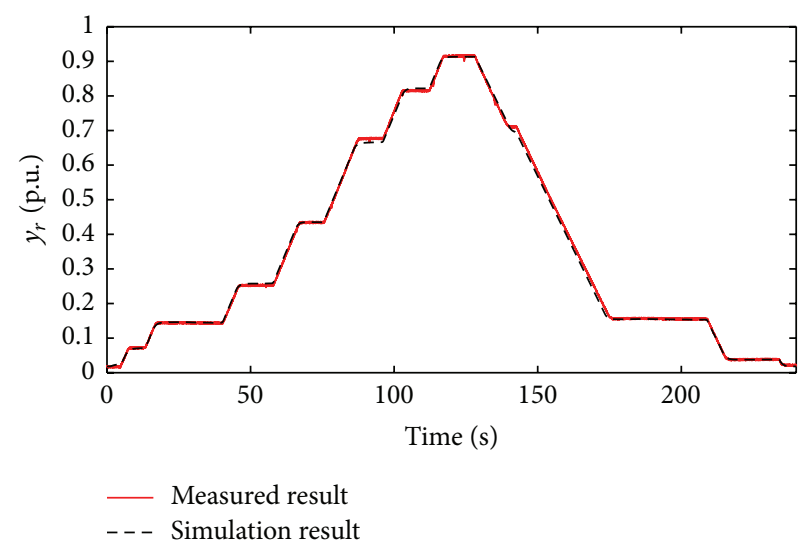

(c)

FIGURE 8: On-cam relationship contrast curves. (a) On-cam relationship fitting curves. (b) Measured gate opening. (c) Simulation and measured blade opening.

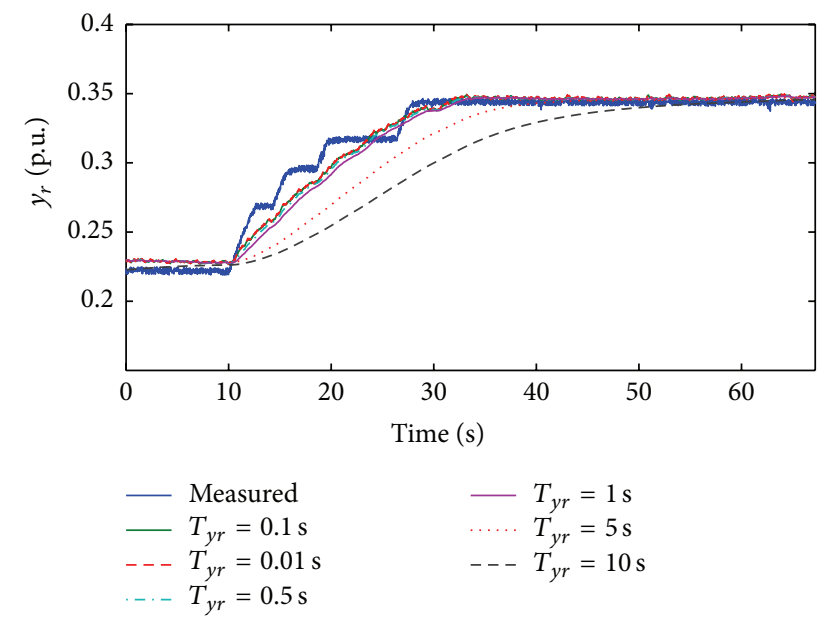

Figure 9: The influence of different $T_{y r}$ on the blade opening.

and other parameters of the double regulating system model identified by the IPSO algorithm. Figure 11 shows the Kaplan turbine regulating system model simulation result using nonlinear Kaplan turbine model for unit frequency disturbance
TABLE 1: The parameter list.

\begin{tabular}{lcc}
\hline Model & Parameter & Value \\
\hline & $K_{s p}$ & 35 \\
Vane control & $T_{y}$ & $28 \mathrm{~s}$ \\
system model & $\mathrm{VEL}_{\text {open }}$ & 0.15 \\
& $\mathrm{VEL}_{\text {close }}$ & -0.15 \\
& $y_{g \mathrm{MAX}}$ & 1 \\
& $y_{g \mathrm{MIN}}$ & 0 \\
\hline & $T_{y r}$ & $1 \mathrm{~s}$ \\
Blade control & $\mathrm{VEL}_{\text {open } 1}$ & 0.020 \\
system model & $\mathrm{VEL}_{\text {close } 1}$ & -0.017 \\
& $y_{r \text { MAX }}$ & 0.9 \\
& $y_{r \text { MIN }}$ & 0 \\
\hline Nonlinear Kaplan & $B_{\text {flow }}$ & 0.6 \\
turbine model & $y_{g}=0.267 y^{3}-1.42 y^{2}+2.383 y-0.5916$ \\
\hline
\end{tabular}

test with disturbance values of $\pm 0.2 \mathrm{~Hz}$ under a certain unit power value. 


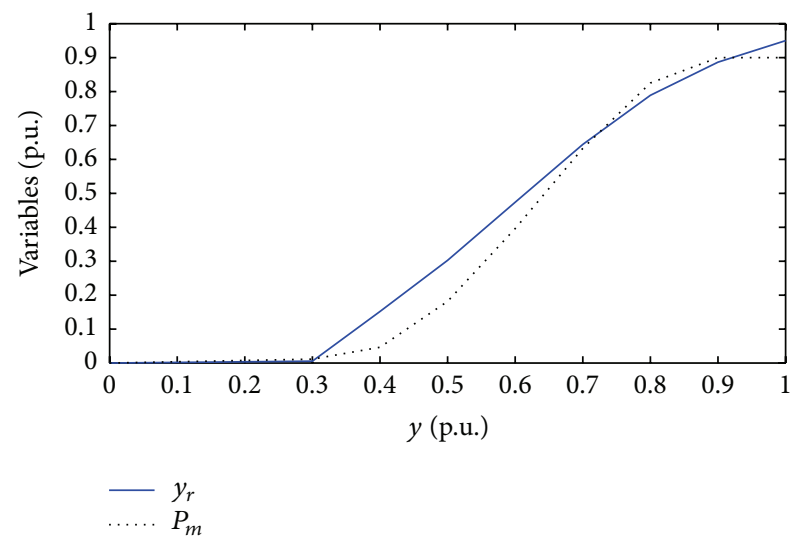

(a)

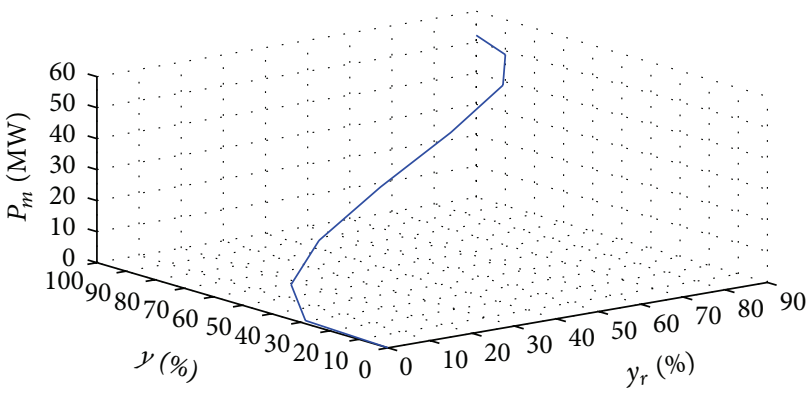

(b)

FIGURE 10: Graphical representation of measured behavior of power acquired at a certain head. (a) 2D space. (b) 3D space.
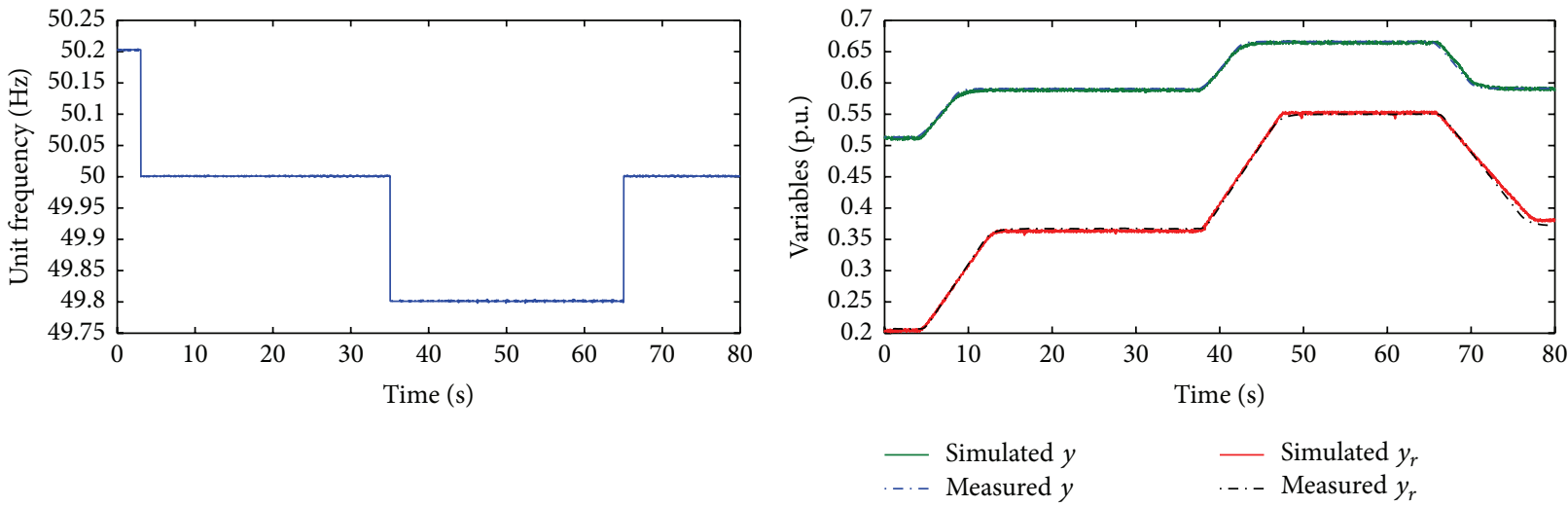

(a)

(b)

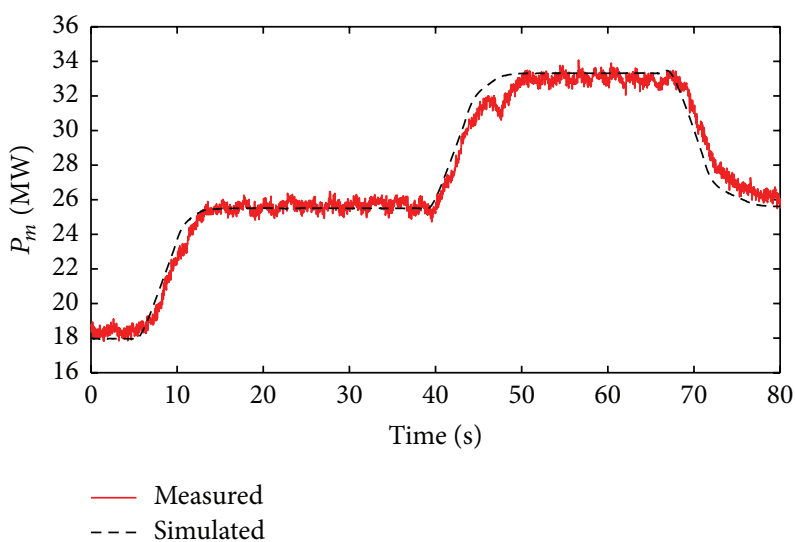

(c)

FIGURE 11: Simulation and measured results of unit frequency disturbance test. (a) Given unit frequency disturbance curve. (b) Wicket gate opening and blade opening curves. (c) Mechanical power curves.

From the simulation results shown in Figure 11, the initial recorded gate opening and blade opening are about 0.5 and 0.2 by per unit, respectively. The blade opening changes linearly under the speed limits effect in the model and the blade opening change is slower than the wicket gate opening change which can be seen from Figure 8 and speed limit differences listed in Table 1. There is little difference at the final mechanical power value due to measured blade opening difference when the unit frequency is recovered to $50 \mathrm{~Hz}$. The wicket gate opening response and the blade opening response 


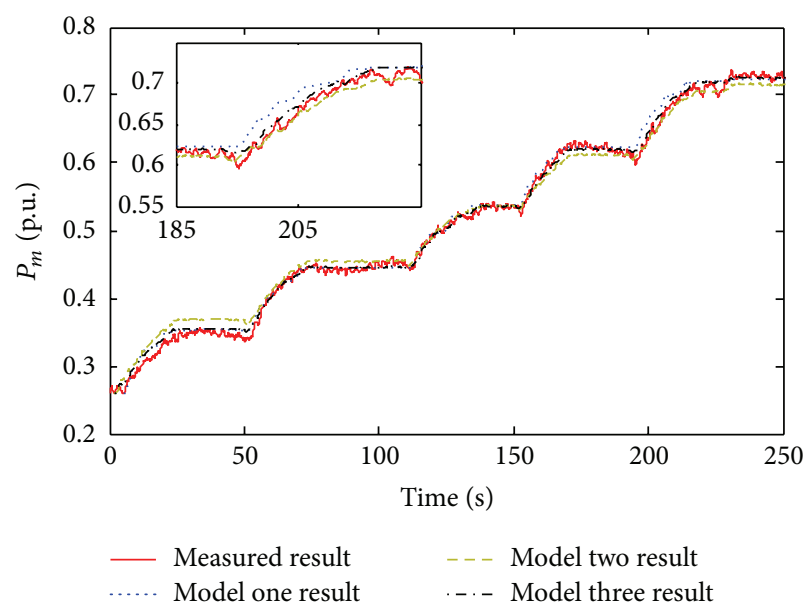

(a)

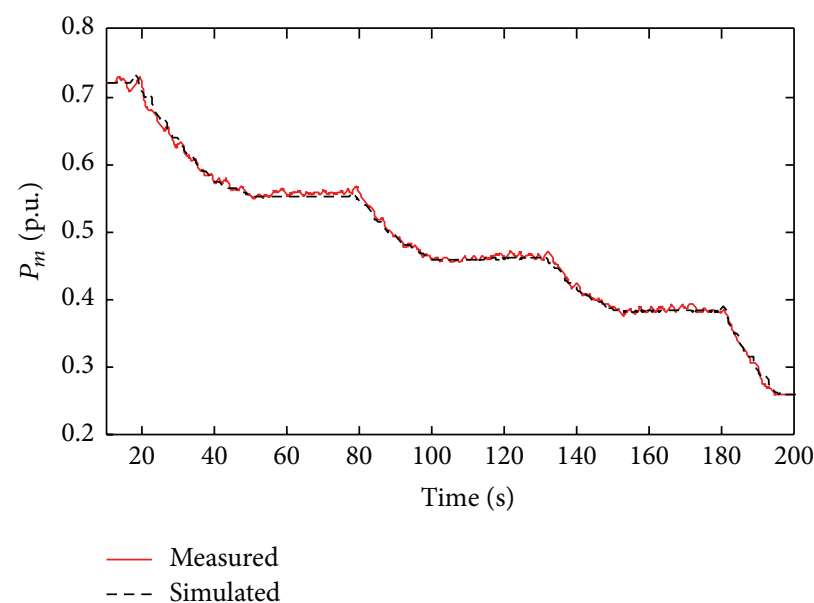

(b)

FIgURE 12: Turbine power output comparison. (a) Turbine power rising disturbance test. (b) Turbine power decreasing disturbance test.

TABLE 2: The parameter list of Kaplan turbine model.

\begin{tabular}{lc}
\hline Model & Parameter \\
\hline & $a=2.3238$ \\
Model one & $b=1.7365$ \\
& $c=2.6712$ \\
& $d=0.5552$ \\
& $f=2.3238$ \\
\hline \multirow{2}{*}{ Model two } & $y_{\mathrm{NL}}=0.3$ \\
& $A_{t}=1.6$ \\
& $T_{w}=1.8 \mathrm{~s}$ \\
\hline
\end{tabular}

TABLE 3: Simulation error comparison of power rising disturbance.

\begin{tabular}{lc}
\hline Turbine model & $\sigma$ \\
\hline Model one & $5.5229 \times 10^{-5}$ \\
Model two & $1.7459 \times 10^{-4}$ \\
Model three & $4.4294 \times 10^{-5}$ \\
\hline
\end{tabular}

results agree with the measured curve indicating that the established vane and blade control model can effectively reflect the dynamic characteristics of Kaplan turbine.

Table 2 shows the identified parameters of the Kaplan turbine and water diversion system model using model one and model two.

Figure 12 shows the comparison results of the turbine power rising test using these three turbine models (i.e., model one, model two, and model three) and decreasing disturbance test using model three with the same Kaplan turbine regulating system mathematical model, respectively. Also, Table 3 lists the power rising disturbance simulation errors of three models.

The Kaplan turbine and water diversion system model using model one (i.e., the linearized Kaplan turbine model) to a certain extent does not accurately reflect the hydroturbine dynamic process when the power output is between 0.62 and 0.72 by per unit value (see Figure 12). As shown in Table 3, model two failed to completely reflect dynamic change of the blade opening and its simulation result has a significant difference with the measured curve. The output of model three (i.e., the nonlinear Kaplan turbine model) is basically the same with the measured curve which is more accurate than model two. In summary, model one and model three apply dual input of the wicket gate opening and the blade opening. These two models regard the effect of blade opening on Kaplan turbine as increasing flow amount and, as a result, influence the unit power output. Through verification of the frequency disturbance test and turbine power disturbance test, the nonlinear Kaplan turbine model can meet the needs of the Kaplan turbine dynamic simulation better.

The generator rotor inertia time constant is obtained by load rejection test. Figure 13 shows the measured curves and the speed fitting result under load rejection of $25 \mathrm{MW}$.

The rotor motion equation is given by

$$
\Delta T_{M}^{*}=T_{j} \cdot \alpha^{*},
$$

where $T_{j}$ is the rotor inertia time constant. $\alpha^{*}$ and $\Delta T_{M}^{*}$ are the rotor acceleration and rotor mechanical torque change by per unit value, respectively. The calculated rotor inertia time constant from linear segment of the speed change between $t 1$ and $t 2$ (see Figure 13(b)) is $5.3 \mathrm{~s}$.

4.4. Grid Connected Simulation Analysis of Kaplan Turbine. The Kaplan turbine regulating system model was established and the simulation was performed on the IEEE 39-bus system [21] with three different kinds of Kaplan turbine and water diversion system models using model one, model two, and model three in Section 3 and the same Kaplan turbine regulating system mathematical model in Section 2, respectively. The Kaplan turbine is connected to bus 18 . Figure 14 shows the revised 39-bus system diagram.

The generator parameters of bus 40 herein are as follows: $X_{d}=1.217, X_{d}=0.600, X_{d}^{\prime}=0.349, X_{q}^{\prime}=0.600, X_{d}^{\prime \prime}=$ 0.250 , and $X_{q}^{\prime \prime}=0.250$, and the rotor inertia time constant of 


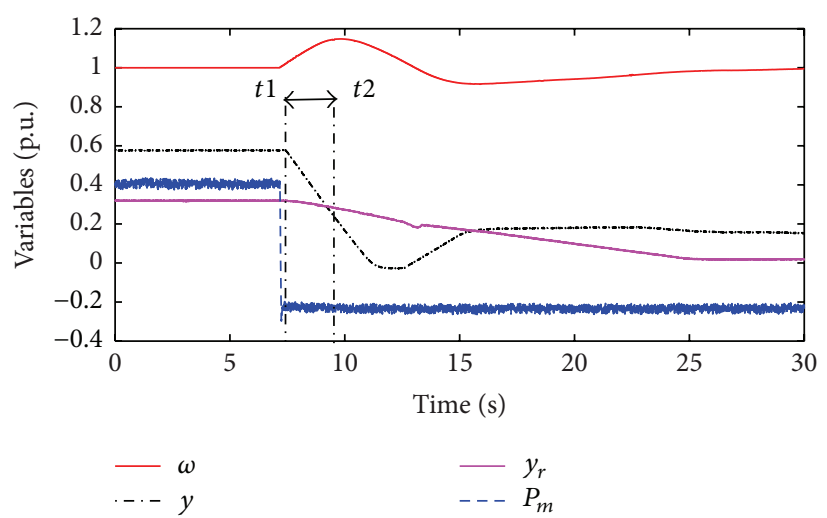

(a)

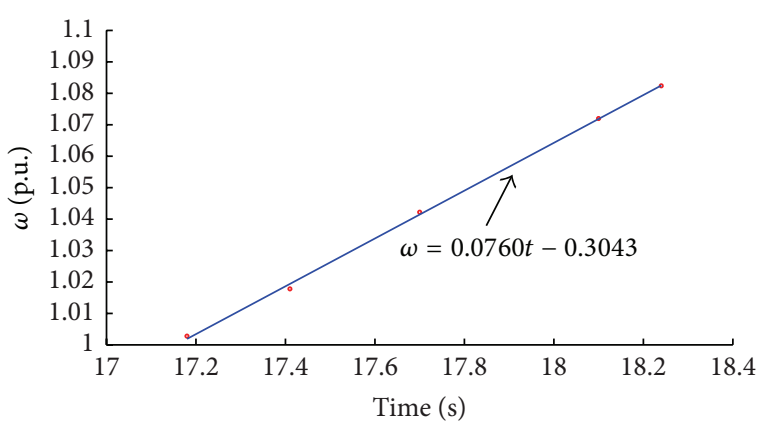

(b)

Figure 13: Load rejection test. (a) Measured variables curves. (b) Linear segment of the speed change and the fitting curve.

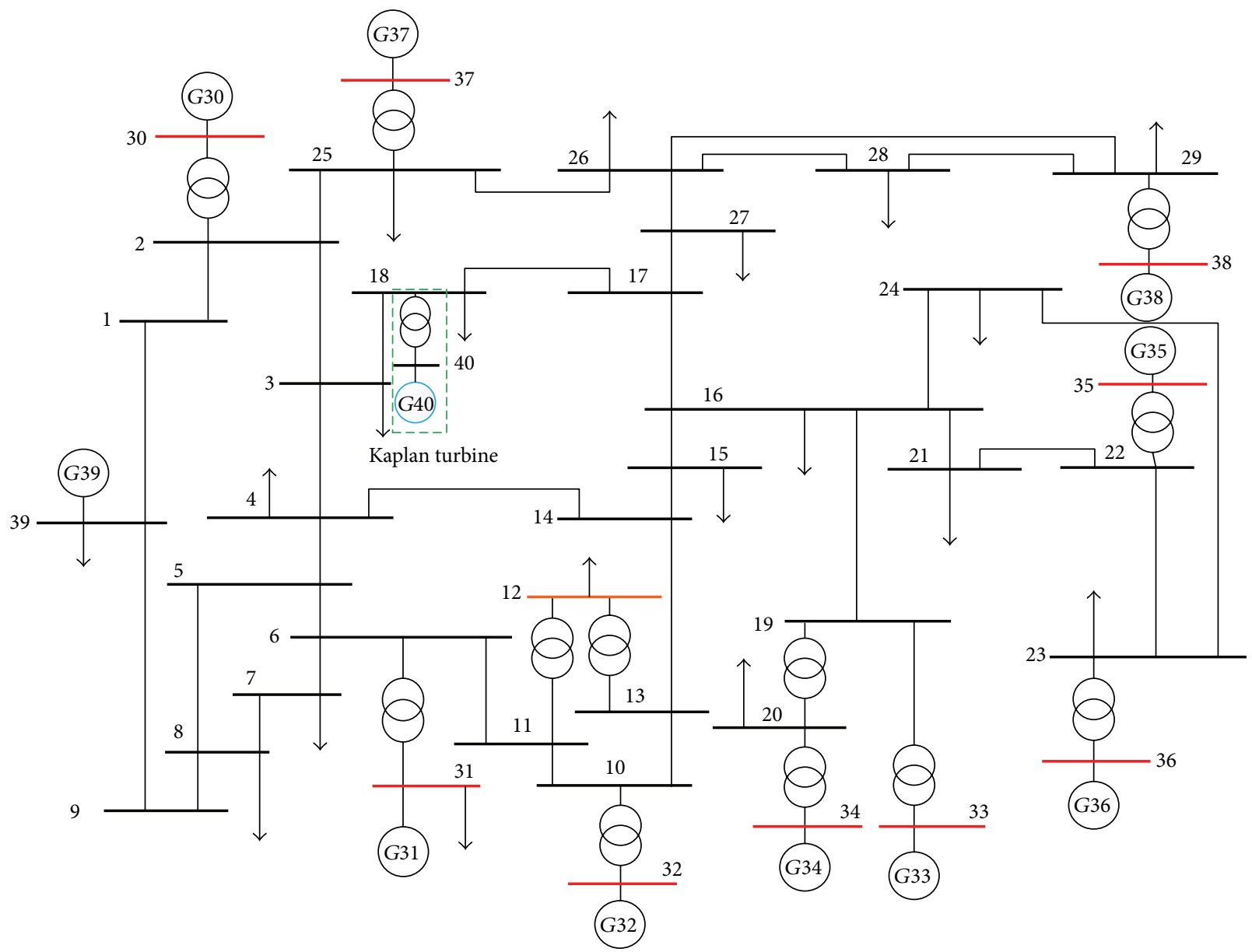

FIGURE 14: Revised 39-bus system diagram.

the generator is $6 \mathrm{~s}$ while the other parameters in the system are not modified.

Assume that there is a three-phase short-circuit fault on lines 17-18 near bus 18 at $1 \mathrm{~s}$, and lines 17-18 are disconnected at $1.1 \mathrm{~s}$. Figure 15 shows the simulation results.

As shown in Figure 15, the terminal voltage of Kaplan turbine is rapidly reduced to around zero when a three-phase short-circuit fault occurs. Each observation returns to the steady-state value after removing the fault line besides the reactive power with value of a little increase. The terminal voltage changes with the three kinds of the turbine regulating system dynamic model (i.e., the Kaplan turbine and water diversion system model using model one, model two, and model three) are basically the same. Under the initial turbine 

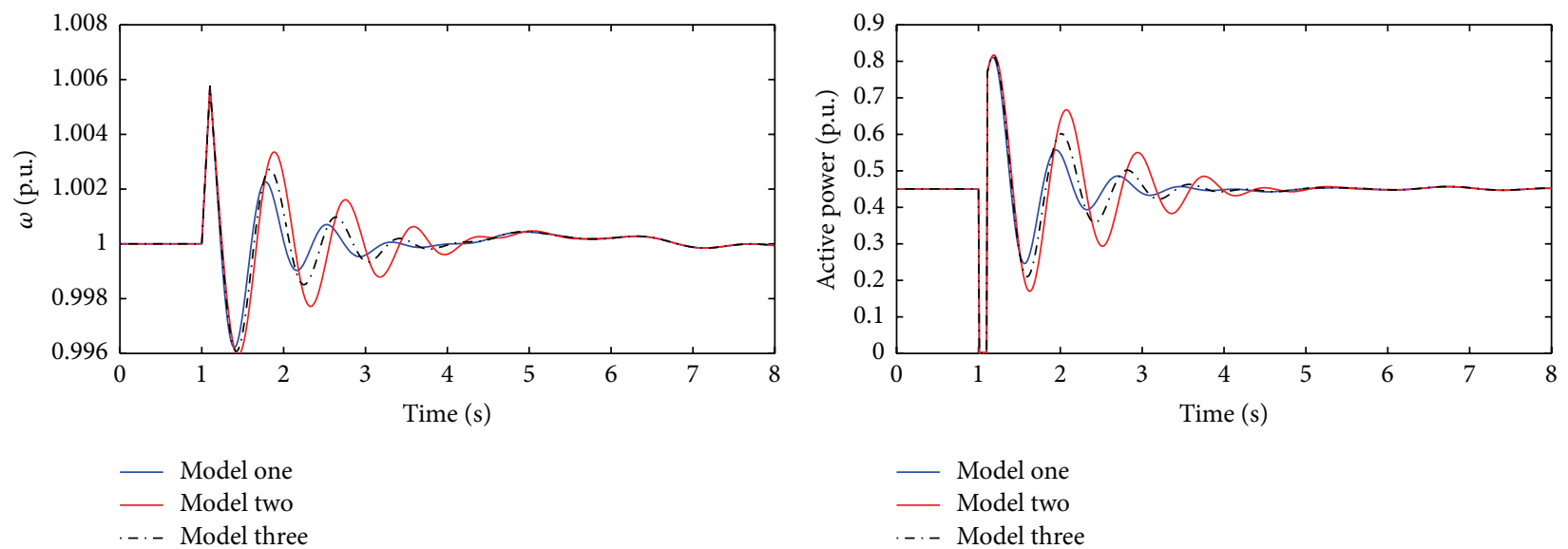

(a)
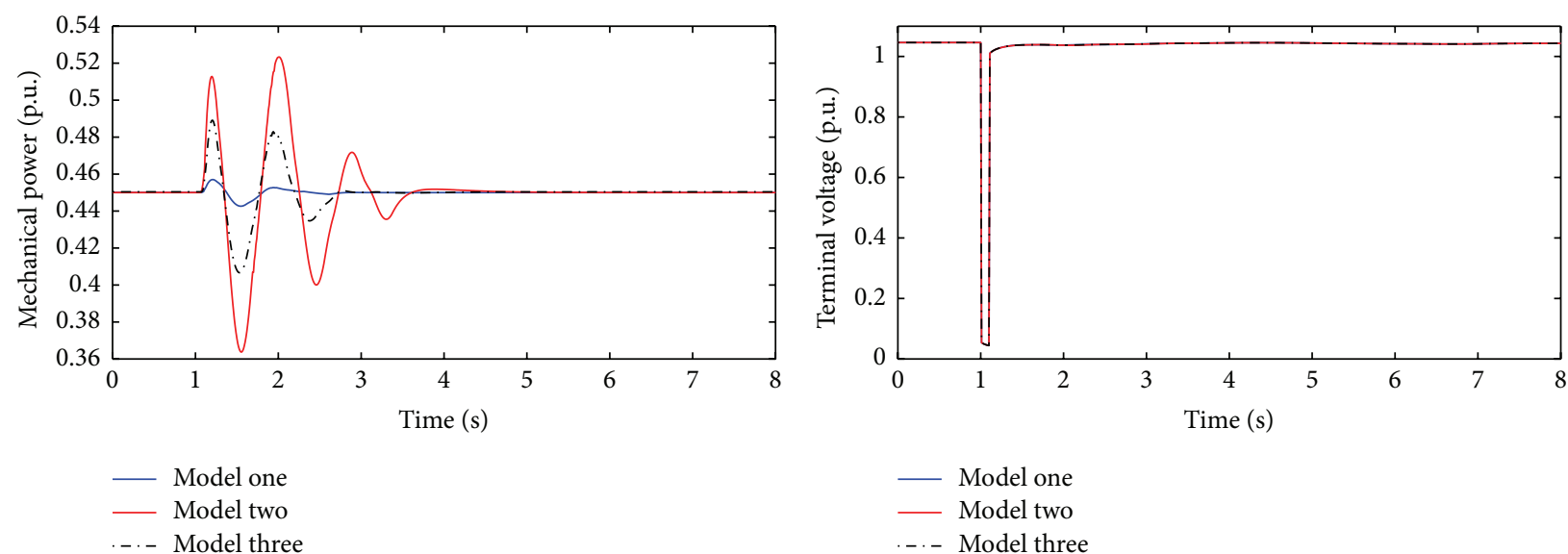

(c)

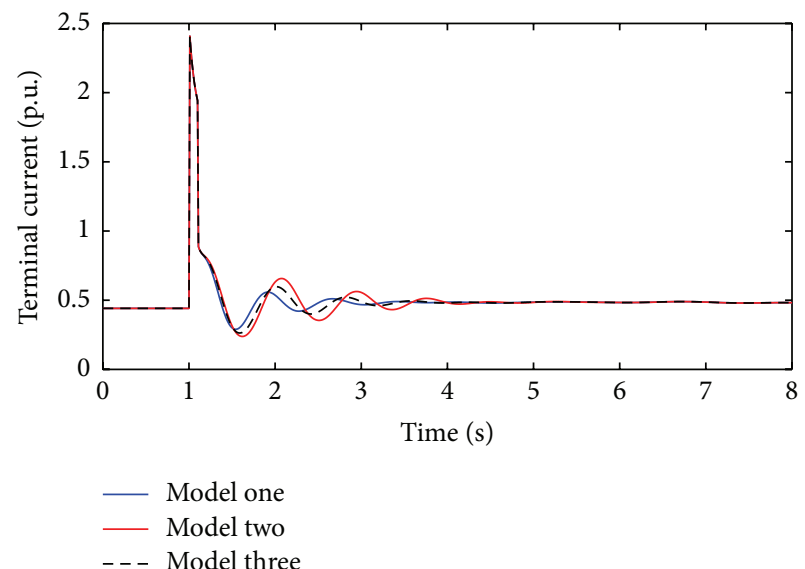

(e)

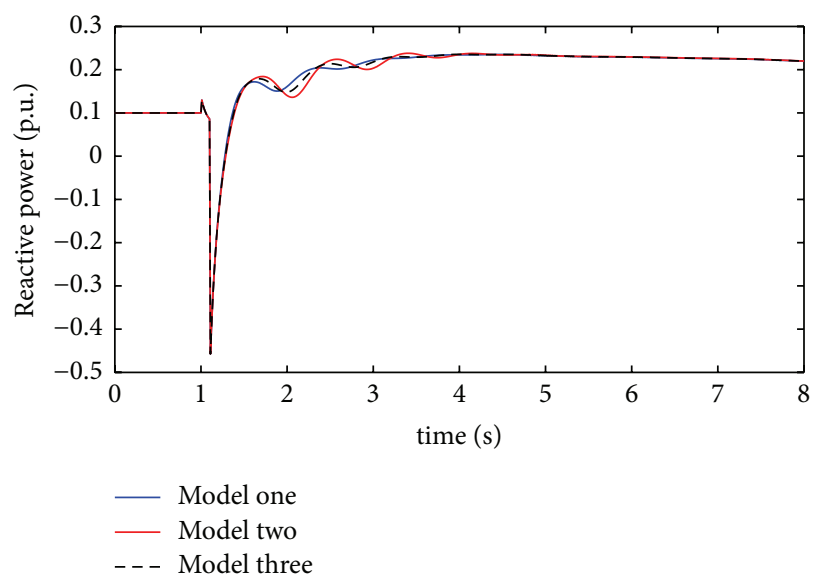

(f)

FIGURE 15: Power grid fault simulation results. (a) Unit speed curves. (b) Active power curves. (c) Mechanical power curves. (d) Terminal voltage curves. (e) Terminal current curves. (f) Reactive power curves.

mechanical power output of 0.45 (i.e., the mechanical power is $27 \mathrm{MW}$ ), the angle speed and the mechanical power fluctuations of model two are larger than those of model one and model three with the maximum deviation being about $0.3 \mathrm{~Hz}$. The maximum mechanical power fluctuation value of model two is about 0.08 by per unit value (the reference capacity of
100 MVA). In addition to different turbine and water diversion system models, the governor parameters (the governor converts the frequency deviation to wicket gate opening) also influence the amount of mechanical power adjustment.

The adjustment of nonlinear turbine model was finer than that of the improved ideal turbine model since the latter was 
derived based on the linearized model near the rated condition and its transfer function was simple. From the turbine operating characteristics, the coefficients in (3) may change significantly with turbine running in other conditions; thus, the original parameters may cause a large amount of power fluctuation.

\section{Conclusion}

Kaplan turbine model in this paper is divided into the governor system model, the blade control system model, and the turbine and water diversion system model. The detailed dual-regulated vane control system model and blade control system model were developed. The comparison of simulation and measured results showed the reasonableness and effectiveness of the established model and parameters. The oncam relationship between the wicket gate opening and the blade opening and the influence of the blade servomotor time constant on the blade control system model were studied. The blade opening was transferred from the blade angle and the fifth order polynomial fitting function could characterize the on-cam relationship with amplitude limits set of the blade opening in this study. The blade servomotor time constant should be set in a reasonable range of value, but it was difficult to be tested. In this study, $T_{y r}$ was $1 \mathrm{~s}$, and thus the blade servomotor response time link could be ignored. However, it had a little effect on the simulation result and simplified the modeling and the experimental work.

Progressively the linearized Kaplan turbine model, improved ideal turbine model, and nonlinear Kaplan turbine model are developed. The nonlinear Kaplan turbine model is proposed which reflects the effects of the wicket gate opening and the blade opening changes on the turbine mechanical power (i.e., it regards the effect of blade opening on Kaplan turbine as increasing flow amount) and has a high accuracy through the comparison of the simulation and the measured results. The power disturbance test and the frequency disturbance test confirmed that the established governor model, the dual-regulated vane and blade control system model, and the nonlinear Kaplan turbine model reflected the dynamic response of the Kaplan turbine adequately, which could be applied in the power system analysis.

\section{Conflict of Interests}

The authors have declared that no conflict of interests exists.

\section{Acknowledgment}

This work was financially supported by the National Natural Science Foundation of China (51307123).

\section{References}

[1] S. Patterson, "Importance of hydro generation response resulting from the new thermal modeling and required hydro modeling improvements," in Proceedings of the IEEE Power Engineering Society General Meeting, vol. 2, pp. 1779-1783, Denver, Colo, USA, June 2004.
[2] D. M. Dobrijevic and M. V. Jankovic, "An improved method of damping of generator oscillations," IEEE Transactions on Energy Conversion, vol. 14, no. 4, pp. 1624-1629, 1999.

[3] I. Vojtko, V. Fecova, M. Kocisko, and J. Novak-Marcincin, "Proposal of construction and analysis of turbine blades," in Proceedings of the 4th IEEE International Symposium on Logistics and Industrial Informatics (LINDI '12), pp. 75-80, IEEE, Smolenice, Slovakia, September 2012.

[4] D. Jošt, A. Škerlavaj, and A. Lipej, "Improvement of efficiency prediction for a Kaplan turbine with advanced turbulence models," Journal of Mechanical Engineering, vol. 60, no. 2, pp. 124-134, 2014.

[5] E. Malenovsky and F. Pochyly, "Dynamic analysis of kaplan turbine caused by short circuit," in Proceedings of the 14th International Symposium on Transport Phenomena and Dynamics of Rotating Machinery, Honolulu, Hawaii, USA, March 2012.

[6] Y. C. Choo, K. M. Muttaqi, and M. Negnevitsky, "Modelling of hydraulic turbine for dynamic studies and performance analysis," in Proceedings of the Australasian Universities Power Engineering Conference, pp. 1-6, December 2007.

[7] L. N. Hannett, J. W. Feltes, and B. Fardanesh, "Field tests to validate hydro turbine-governor model structure and parameters," IEEE Transactions on Power Systems, vol. 9, no. 4, pp. 1744-1751, 1994.

[8] Working Group, "Hydraulic turbine and turbine control models for system dynamic studies," IEEE Transactions on Power Systems, vol. 7, no. 1, pp. 167-179, 1992.

[9] D. H. Thorne and E. F. Hill, "Field testing and simulation of hydraulic turbine governor performance," IEEE Transactions on Power Apparatus and Systems, vol. 93, no. 4, pp. 1183-1191, 1974.

[10] Q. Lu, W. Hu, J. Li, and J. Zhou, "Research on frequency simulation model and control strategy of hydropower islands," in Proceedings of the International Conference on Advanced Power System Automation and Protection (APAP '11), vol. 3, pp. 18961901, IEEE, Beijing, China, October 2011.

[11] J. L. Agüero, M. C. Beroqui, and F. Issouribehere, "Grid frequency control. secondary frequency control tuning taking into account distributed primary frequency control," in Proceedings of the IEEE Power and Energy Society General Meeting, pp. 1-8, IEEE, Minneapolis, Minn, USA, July 2010.

[12] P. Schniter and L. Wozniak, "Efficiency based optimal control of Kaplan hydrogenerators," IEEE Transactions on Energy Conversion, vol. 10, no. 2, pp. 348-353, 1995.

[13] P. Huvet, "Influence of runner blade angle variations on Kaplan turbine transients," Houille Blanche, vol. 41, no. 1, pp. 137-147, 1986.

[14] D. N. Kosterev, "Hydro turbine-governor model validation in pacific northwest," IEEE Transactions on Power Systems, vol. 19, no. 2, pp. 1144-1149, 2004.

[15] M. Brezovec, I. Kuzle, and T. Tomisa, "Nonlinear digital simulation model of hydroelectric power unit with Kaplan turbine," IEEE Transactions on Energy Conversion, vol. 21, no. 1, pp. 235241, 2006.

[16] W. Zhao and D. Wei, "Relevance vector machine combined with glowworm swarm optimization for cam relationship of Kaplan turbine," Advanced Science Letters, vol. 11, no. 1, pp. 244-247, 2012.

[17] D. Kranjcic and G. Stumberger, "Differential evolution-based identification of the nonlinear kaplan turbine model," IEEE Transactions on Energy Conversion, vol. 29, no. 1, pp. 178-187, 2014. 
[18] M. Djukanovic, M. Novicevic, D. Dobrijevic, B. Babic, D. J. Sobajic, and Y.-H. Pao, "Neural-net based coordinated stabilizing control for the exciter and governor loops of low head hydropower plants," IEEE Transactions on Energy Conversion, vol. 10, no. 4, pp. 760-767, 1995.

[19] J. Zhao, L. Wang, D. Liu, and J. Wang, "Piecewise model and parameter obtainment of governor actuator in turbine," Journal of Applied Mathematics, vol. 2015, Article ID 709272, 9 pages, 2015.

[20] E. De Jaeger, N. Janssens, B. Malfliet, and F. Van De Meulebroeke, "Hydro turbine model for system dynamic studies," IEEE Transactions on Power Systems, vol. 9, no. 4, pp. 1709-1715, 1994.

[21] M. D. Amadou, H. Mehrjerdi, S. Lefebvre, M. Saad, and D. Asber, "Area voltage control analysis in transmission systems based on clustering technique," IET Generation, Transmission \& Distribution, vol. 8, no. 12, pp. 2134-2143, 2014. 


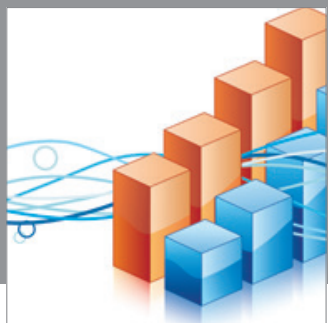

Advances in

Operations Research

mansans

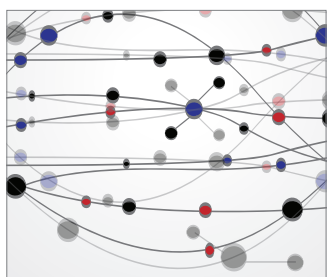

The Scientific World Journal
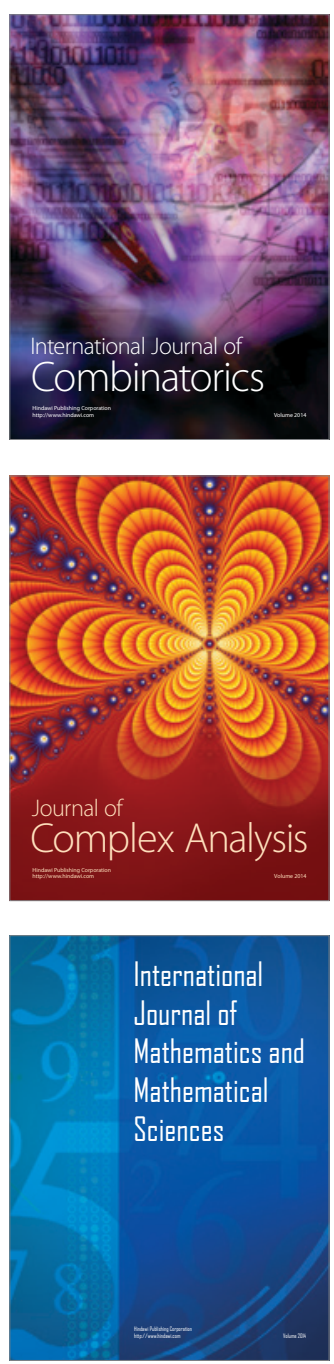
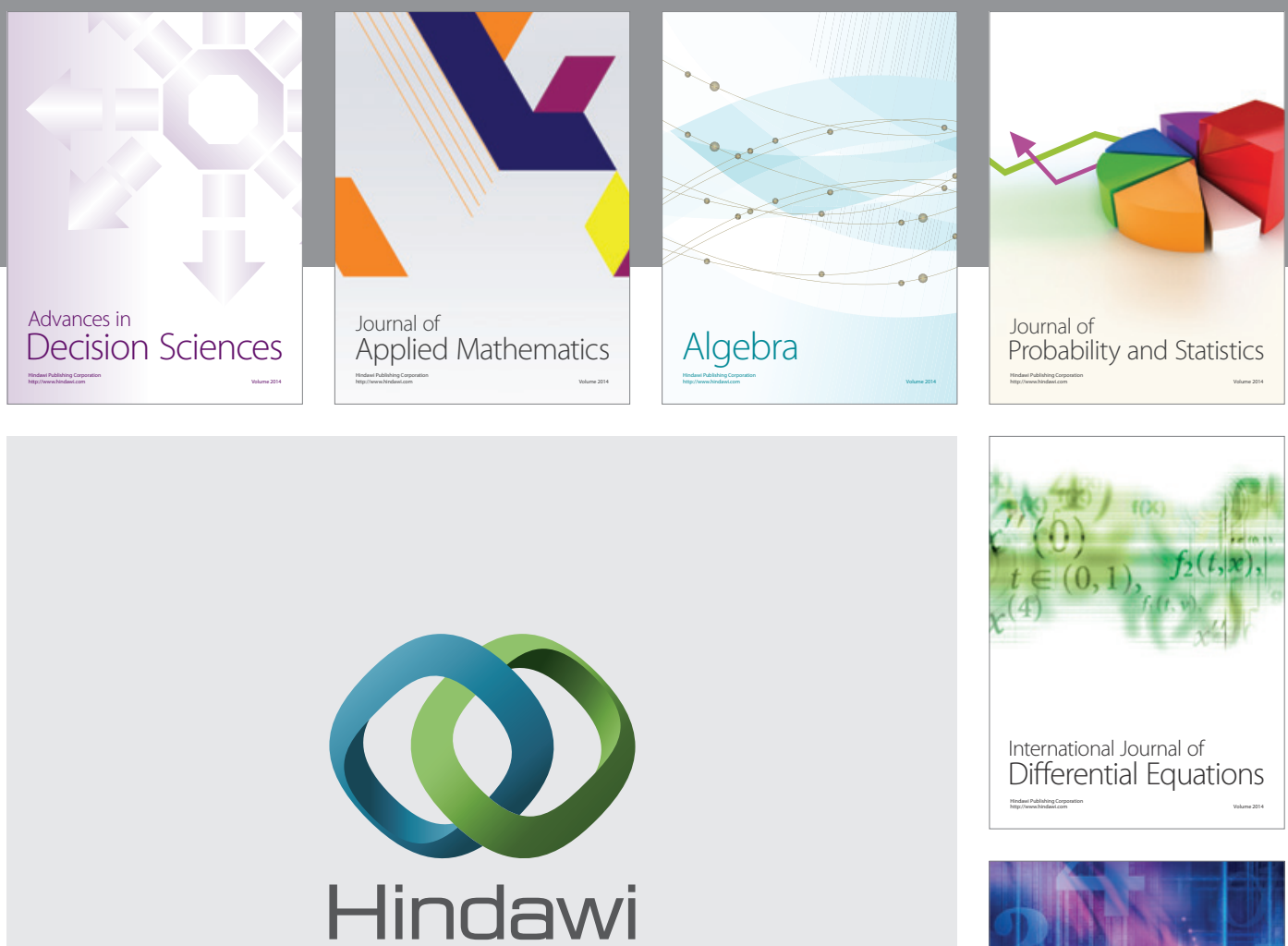

Submit your manuscripts at http://www.hindawi.com
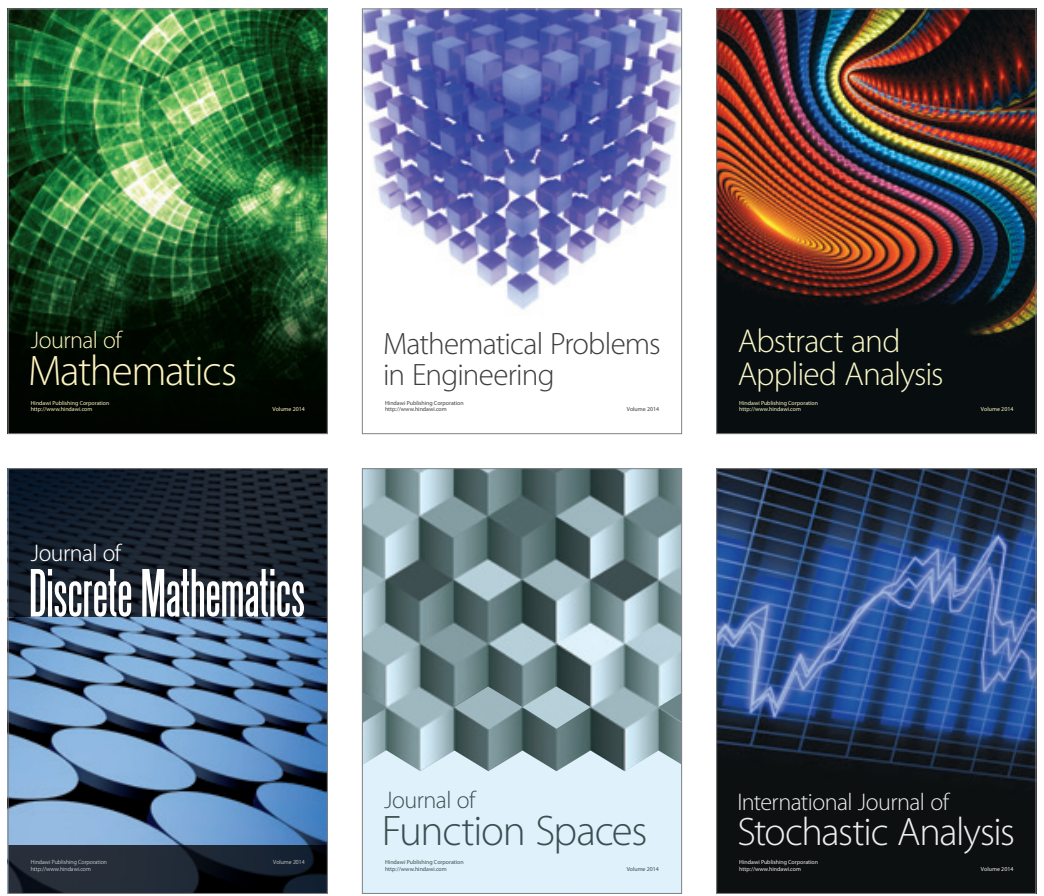

Journal of

Function Spaces

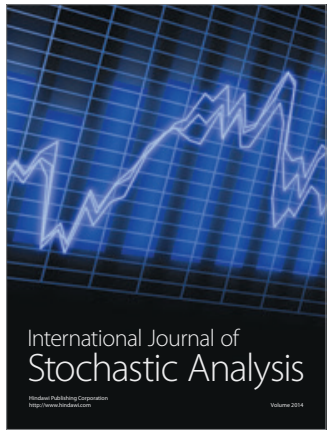

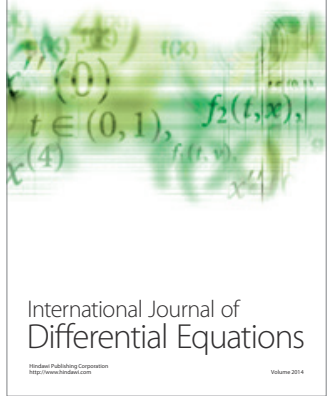
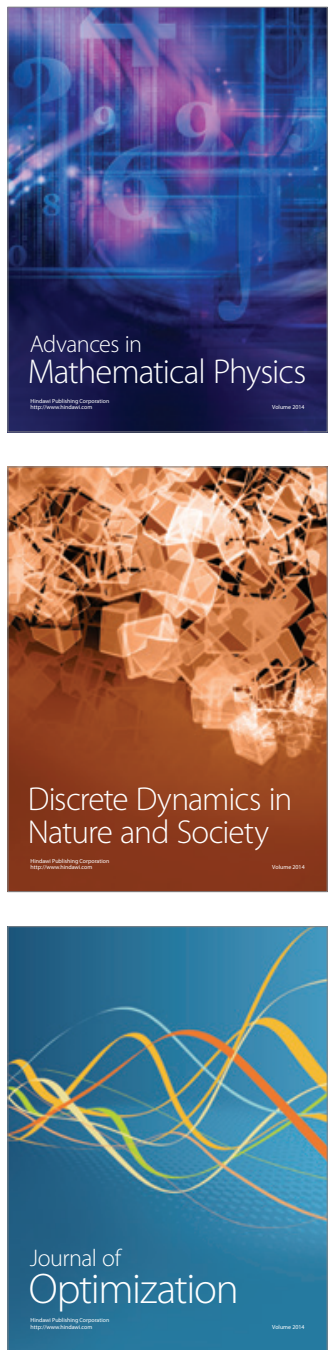